\title{
Postpartum dönemde demir eksikliği anemisi olan hastalarda intravenöz ve oral demir tedavisinin karşılaştırılması
}

\section{Comparison of intravenous and oral iron treatment in patients with iron deficiency anemia in postpartum period}

\author{
Pınar KADIROĞULLARI*, Kerem Doğa SEÇKIN, Olgu İçten BAFALI, İbrahim POLAT
}

Sağlık Bilimleri Üniversitesi, Kanuni Sultan Süleyman Eğitim ve Araştırma Hastanesi, Obstetrik ve Jinekoloji Kliniği, İstanbul/TÜRKiYE

\section{öz}

Amaç: Kadınlarda postpartum demir eksikliği anemisi oldukça yaygındır. Çoğu kadın oral veya intravenöz (iv) demir ile ya da kan transfüzyonu ile tedavi edilir. Bu çalışmanın amacı, intravenöz ferrik karboksimaltozun postpartum anemisi olan kadınlarda ferröz sülfatla karşılaştırıldığında etkinliğini, güvenilirliğini ve tolere edilebilirliğini değerlendirmektir.

Gereç ve Yöntemler: Çalışmamız postpartum 1.günde hemoglobin değeri 8 ile $10 \mathrm{~g} / \mathrm{dl}$ arasında olan hastalardan, hastanede yatışı süresince iv demir tedavisi verilen ve taburculuk sonrası oral demir tedavisi alan hastaların dosyalarının incelenmesi ile oluşturuldu. 1.grubu oluşturan hastalar; postpartum 1.günde 15mg/kg den maksimum 1000 mg iv ferrik karboksimaltoz tedavisi alan (n:100), 2.grubu oluşturan hastalar ise postpartum taburculuk ile beraber oral ferroz sulfat (100 mg) / 2x1 den 6 hafta boyunca tedavisi düzenlenen hastalardı (n:100). Her iki grupta yer alan hastaların sistem üzerinden bilgileri ve tetkik sonuçları incelendi ve postpartum 1.gün, 14.gün ve 40.gün hemoglobin, hematokrit ve ferritin düzeyleri kaydedildi.

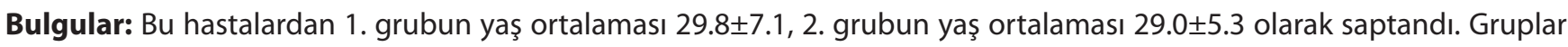
arasında gravida ve parite sayıları, doğum şekilleri ve tedavi öncesi bakılan hemoglobin (Hb) ve hematokrit (Htc) değerleri arasında fark yoktu. Tedavi sonrası 1. Gün bakılan Hb ve Htc değerleri iv demir tedavisi alan 1.grupta, oral demir tedavisi alan 2.gruba göre anlamlı derecede yüksekti ( $p<0.005)$. İv demir tedavisinin $\mathrm{Hb}$ ve Htc değerlerini hızlı artırdığı saptandı. 14. Gün bakılan $\mathrm{Hb}$, Htc ve ferritin değerleri ortalaması 1. grupta anlamlı olarak daha yüksekti $(p<0.005)$. Gruplar arasında 40. Gün bakılan parametrelerde anlamlı fark görülmedi.

Tartışma: Postpartum demir eksikliği anemisinin tedavisinde intravenöz ferrik karboksimaltoz güvenli ve iyi tolere edilebilmektedir. Intravenöz demir tedavisinin postpartum anemisi olan kadınlarda hemoglobin seviyesini oral ferröz sülfattan daha hızlı arttırdığı gösterilmiştir. Ayrıca demir depolarını daha hızlı bir şekilde doldurduğu görülmüştür.

Anahtar kelimeler: Demir karboksimaltoz; Demir sülfat; İntravenöz tedavi; Oral tedavi; Postpartum demir eksikliği anemisi

Sorumlu Yazar*: Pınar KADíROĞULLARI, Sağlık Bilimleri Üniversitesi, Kanuni Sultan Süleyman Eğitim ve Araştırma Hastanesi, Obstetrik ve Jinekoloji Kliniği, İstanbul/TÜRKIYE

Eposta: pinarsezer33@hotmail.com

Received : 09.10.2018 Accepted: 17.11.2018

Doi: $10.18663 /$ tjcl.468809 


\section{ABSTRACT}

Aim: The aim of the study is to evaluate the efficacy, safety and tolerability of intravenous ferric carboxymaltose in women with postpartum anemia compared to oral ferrous sulfate.

Material and Methods: Our study was created by reviewing the records from patients who had hemoglobin levels between 8 and $10 \mathrm{~g} / \mathrm{dl}$ on postpartum first day, and those who received intravenous iron treatment during hospitalization and who received oral iron treatment after discharge. Patients in group 1; In the postpartum first day, patients who were treated with ferric carboxymaltose treatment at a rate of $15 \mathrm{mg} / \mathrm{kg}$ maximum $1000 \mathrm{mg}$ and patients in the second group were treated with oral ferrous sulphate $(100 \mathrm{mg}) 2 \times 1$ for 6 weeks after postpartum discharge. The data of the patients in both groups and their results were analyzed and hemoglobin, hematocrit and ferritin levels were recorded on the postpartum 1st, 14 th and 40 th day.

Results: The mean age of these patients was $29.8 \pm 7.1$ in group 1, and $29.0 \pm 5.3$ in group 2, respectively. There was no significant difference between the groups in terms of gravidity, parity numbers, delivery patterns and $\mathrm{Hb}$ and $\mathrm{Htc}$ levels before the treatment. The $\mathrm{Hb}$ and $\mathrm{Htc}$ levels on first day after treatment were significantly higher in the group 1 received iv iron treatment compared to the group 2 received oral iron therapy $(\mathrm{p}<0.005)$. Iv iron treatment was found to increase $\mathrm{Hb}$ and Htc levels rapidly. The mean of $\mathrm{Hb}$, Htc and ferritin levels on 14th day was significantly higher in group $1(\mathrm{p}<0.005)$. No significant difference was observed between the groups at the 40th day.

Discussion: Intravenous ferric carboxymaltose is safe and well tolerated in the treatment of postpartum iron deficiency anemia. Intravenous iron therapy increases the hemoglobin levels in women with postpartum anemia faster than oral ferrous sulphate. It also fills iron store more quickly.

Keywords: Ferric carboxymaltose; Ferrous sulfate; Intravenous treatment; Oral treatment; Postpartum iron deficiency anemia

\section{Giriş}

Anemi, anne ve fetüsde önemli morbidite yapabilen ciddi bir risk faktörüdür. Dünya Sağlık Örgütü postpartum anemiyi <12 g/dl olarak tanımlar [1,2]. Demir eksikliği anemisi hipokromik mikrositer eritrositler ve düşük ferritin seviyeleri ile karakterizedir [3]. Postpartum birinci haftada \%37 gibi yüksek oranlarda demir eksikliği anemisi tariflenmiştir [3,4]. Demir eksikliği anemisi yorgunluk, baş ağrısı, baş dönmesi, nefes darlığı, çarpıntı, azalmış kognitif fonksiyonlar ve depresyon ile kendini gösterebilir $[4,5,6]$. Postpartum anemi, gebelik öncesi ve gebelik boyunca yetersiz demir alımı ve peripartum kan kaybı nedeniyle ortaya çıkar [7,8,9]. Postpartum anemi doğum sonrası hastanede uzun kalma süresi, kan transfüzyonu ve yüksek hastane masraflarına neden olur $[1,9,10]$. Bundan dolayı postpartum anemi yüksek dikkat ve bakım gerektirir.

Demir eksikliği anemisi olanlarda günümüzde majör tedavi oral demirdir [11]. Ancak oral demir tedavisinin gastrointestinal yan etkilerinin olması ve bu sebeple hasta uyumsuzluğu olması tedaviyi kısıtlamaktadır. Bunun sonucu olarak daha büyük ve daha hızlı demir kaynağı sağlayan parenteral demir tedavisine artan bir ilgi mevcuttur $[12,13]$. Intravenöz preparat olarak demir dekstran, sodyum ferroz glukonat demir sukroz kullanılabilir. Bu preparatların depoları doldurmak için düşük dozlarda çok sayıda verilmesi gerekliliği, infüzyon sürelerinin uzun olması (sodyum ferroz glukonat) ve artmış hipersensitivite reaksiyonları ile ilişkili olması (demir dekstran) kısıtlı özellikleridir [14]. Demir dekstran hayatı tehdit eden hipersensitivite reaksiyonu, anaflaktik reaksiyon, artralji, myalji ve ateş yapabilir.

Ferrik karboksimaltoz (Ferinject ${ }^{\mathrm{TM}}$ ), non-dekstran, hipersensitivite ve anaflaksi riski çok düşük olan, test dozunun gerekli olmadığı yeni bir intravenöz (iv) demir kompleksidir $[15,16] .1000 \mathrm{mg}$ a kadar tek doz ve 15-30 dakika (dk) kadar kısa sürede infüzyonu yapılabilir $[15,16,17]$. Ferrik karboksimaltoz tedavisi, oral tedavinin gastrointestinal yan etkilerinin üstesinden gelmesi, kısa hastanede kalış süresi ve maliyeti azaltması nedeniyle tercih edilmektedir. Ferrik karboksimaltozun neredeyse nötral pH'ya ve fiziksel osmolariteye sahip olması tek doz ve kısa periyodda verilmesini bu da diğer parenteral tedavilere üstünlüğünü sağlamaktadır [18]. Biz de çalışmamızda intravenöz demir tedavilerinden olan ferrik karboksimaltozun postpartum dönemde, oral demir tedavisine göre üstün olup olmadığını göstermeyi amaçladık. 


\section{Gereç ve Yöntemler}

Çalışmamız retrospektif olarak planlanmış olup, Ocak 2016- Ocak 2018 tarihleri arasında üçüncü basamak referans merkezi olan İstanbul Sağlık Bilimleri Üniversitesi Kanuni Sultan Süleyman Eğitim ve Araştırma Hastanesi Kadın Hastalıkları ve Doğum Kliniğinde doğum yapmış hastalardan, postpartum anemisi olanlarda ilgili klinik ve etik kurul onayı alındıktan sonra yapılmıştır.

Doğum sonrası hastaneden taburcu edilmeden önce, postpartum 1.günde, hemoglobin değerine bakılan hastaların hemoglobin değeri 8 ile $10 \mathrm{~g} / \mathrm{dl}$ arasında olanlarından hemodinamik olarak stabil olan 200 kadın hasta çalışmaya dahil edildi. Hastanede yatışı süresince intravenöz tedavi verilenler ve taburculuk sonrası oral demir tedavisi alan hastaların dosyaları tarandı. Ciddi postpartum vajinal kanaması olan hastalar, demir intoleransı olan hastalar, peripartum kan transfüzyonu yapılanlar, myelosupresif tedavi alanlar, astım, pulmoner tromboemboli ve alkol kullanım hikayesi olanlar, renal-hepatik enfeksiyonu olanlar çalışma dışı bırakıldı. Çalışma sırasında ek bir müdahaleye gereksinim duyan hastalar da (çalışma protokolü dışında eritropoietin, kan transfüzyonu, intravenöz veya oral demir tedavisi alanlar) çalışma dışı bırakıldı. 1.grubu oluşturan hastalar; postpartum 1.günde $15 \mathrm{mg} / \mathrm{kg}$ den maksimum $1000 \mathrm{mg}$ iv ferrik karboksimaltoz tedavisi alan, 2.grubu oluşturan hastalar ise postpartum taburculuk ile beraber oral ferroz sulfat (100 mg) / 2x1 den 6 hafta boyunca tedavisi düzenlenen hastalardı. Bu hastaların yaş, gravida, parite, doğum şekli gibi bilgileri dosyalarından kaydedildi. İv ferrik karboksimaltoz tedavisi alan hastaların infüzyon sırasındaki yan etkilerine (flushing, alerji, sıcak basması, başağrısı, yorgunluk) kayıtlardan ulaşıldı. Oral tedavi alan gruptaki hastaların sistemden, poliklinik kayıtlarından yan etki bilgilerine ve ilaç kullanım düzenlerine ulaşıldı. Her iki grupta yer alan hastaların sistem üzerinden tetkik sonuçları incelendi ve postpartum 1.gün, 14.gün ve 40.gün hemoglobin, hematokrit ve ferritin düzeyleri incelendi.

Veriler bilgisayar ortamında sınıflandırıldı ve IBM Statistical Package for the Social Sciences versiyon 20 (SPSS Inc., Chicago, IL, USA) programı kullanılarak analiz edildi. Sürekli değişkenler için ortalama \pm standart sapma, kategorik değişkenler için yüzde ve sayı değerleri verildi. Grupların normal dağılıma uygun olup olmadığı Kolmogorov Smirnov testi ile değerlendirildi ve dağılım sonucuna göre ortalamaların karşılaştırılması için Mann Whitney $U$ veya Student $T$ testi uygulandı. Kategorik değişkenlerin karşılaştırılması için Ki-kare ve Fisher'sexact testleri kullanıldı. Sonuçlarda $\mathrm{p}<0.05$ değeri istatistiksel olarak anlamlı kabul edildi.

\section{Bulgular}

Çalışmaya dahil edilen hastaların postpartum 1.günde bakılan hemoglobin değeri 8 ile $10 \mathrm{~g} / \mathrm{dl}$ arasında idi. 1. grubun yaş ortalaması 29.8 7.1 (17-47), 2.grubun yaş ortalaması 29.0 \pm 5.3 (20-41) olarak saptandı. Hastaların gravida ve parite sayıları arasında anlamlı fark yoktu. 1.grupta 30 hasta normal vajinal yolla doğum yapmış iken 70 hasta sezaryen ile doğum yaptı. 2.grupta 29 hasta normal vajinal yolla doğum yapmış iken, 71 hasta sezaryen ile doğum yaptı. Gruplar arasında doğum şekli açısından anlamlı fark saptanmadı. Hastaların demografik ve karakteristik özellikleri Tablo 1'de belirtilmiştir.

\begin{tabular}{|c|c|c|c|}
\hline & $\begin{array}{c}\text { 1. Grup } \\
\text { İntravenöz Demir } \\
(\mathrm{n}: 100)\end{array}$ & $\begin{array}{l}\text { 2.Grup } \\
\text { Oral Demir } \\
\text { (n:100) }\end{array}$ & $\begin{array}{c}P \\
\text { Değeri }\end{array}$ \\
\hline $\begin{array}{l}\text { Doğum öncesi Hb (g/L) } \\
\text { Mean } \pm \text { SD }\end{array}$ & $\begin{array}{l}11.9 \pm 1.0 \\
(7-12)\end{array}$ & $\begin{array}{c}10.3 \pm 1.0 \\
(8-12)\end{array}$ & 0.005 \\
\hline $\begin{array}{l}\text { Doğumöncesi Htc (g/L) } \\
\text { Mean } \pm \text { SD }\end{array}$ & $\begin{array}{c}32.6 \pm 2.8 \\
(24-39)\end{array}$ & $\begin{array}{c}32.7 \pm 2.9 \\
(28-39)\end{array}$ & 0.732 \\
\hline $\begin{array}{l}\text { Yaş (yıl) } \\
\text { Meant SD }\end{array}$ & $\begin{array}{c}29.8 \pm 7.1 \\
(17-47)\end{array}$ & $\begin{array}{c}29.0 \pm 5.3 \\
(20-41)\end{array}$ & 0.390 \\
\hline $\begin{array}{l}\text { Gravida } \\
\text { Mean } \pm \text { SD }\end{array}$ & $\begin{array}{c}2.6 \pm 1.2 \\
(1-6)\end{array}$ & $\begin{array}{c}2.4 \pm 1.0 \\
(1-4)\end{array}$ & 0.090 \\
\hline $\begin{array}{l}\text { Parite } \\
\text { Mean } \pm \text { SD }\end{array}$ & $\begin{array}{c}2.4 \pm 1.1 \\
(1-6)\end{array}$ & $\begin{array}{c}2.2 \pm 1.0 \\
(1-4)\end{array}$ & 0.119 \\
\hline $\begin{array}{l}\text { Doğum şekli [n ( \% )] } \\
\text { Vajinal } \\
\text { Sezaryen }\end{array}$ & $\begin{array}{l}30(\% 30) \\
70(\% 70)\end{array}$ & $\begin{array}{l}29(\% 29) \\
71(\% 71)\end{array}$ & 0.877 \\
\hline \multicolumn{4}{|c|}{$\mathrm{Hb}$ : hemoglobin , Htc : hematokrit } \\
\hline
\end{tabular}

1.gruptaki hastaların doğum öncesi $\mathrm{Hb}$ değerleri ortalaması $11.9 \pm 1.0$ (7-12) g/L, Htc değerleri ortalaması 32.6 \pm 2.8 (24-39) $\mathrm{g} / \mathrm{L}$ olarak saptandı. 2.gruptaki hastaların ise doğum öncesi $\mathrm{Hb}$ değerleri ortalaması 10.3 \pm 1.0 (8-12) g/L, Htc değerleri ortalaması 32.7 2.9 (28-39) g/L olarak saptandı. Gruplar arası doğum öncesi $\mathrm{Hb}$ ve Htc değerleri 1.gruptaki hastalarda daha yüksekti.

Doğum sonrası 1.gün bakılan $\mathrm{Hb}$ değerleri ortalaması iv demir tedavisi alan 1.grupta; $8.5 \pm 0.8$ (7-10) g/L, Htc ortalaması 27.7 \pm 1.9 (22-32) g/L olarak saptandı. Oral demir tedavisi alan 2.grupta ise $\mathrm{Hb}$ değerleri ortalaması $9.1 \pm 0.9$ (6.9-11.5) g/L, Htc ortalaması 29.3 \pm 2.7 (22.5-35.9) g/L idi. Tedavi sonrası 1. gün bakılan Hb ve Htc değerleri 1.grupta 2.gruba göre anlamlı derecede yüksekti ( $p<0.005)$.

14.gün kontrole çağrılan hastaların $\mathrm{Hb}$ değerleri, Htc değerleri, ve ferritin değerleri ortalamalarına bakıldı. 1. Grupta 


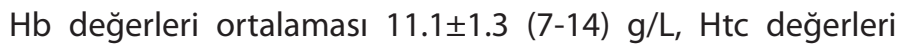
ortalaması $37.2 \pm 2.9(32-43) \mathrm{g} / \mathrm{L}$ ve ferritin değerleri ortalaması 463.8 $\pm 402.2(19-262) \mathrm{g} / \mathrm{L}$ bulundu. 2. grupta ise $\mathrm{Hb}$ değerleri ortalaması 10.6 $\pm 1.2(7.9-14) \mathrm{g} / \mathrm{L}$, Htc değerleri ortalaması $35.1 \pm 4.1$ (27-44.9) $\mathrm{g} / \mathrm{L}$ ve ferritin değerleri ortalaması 84.9 \pm 204.5 (4.4-1071) g/L idi. Her iki gruptaki Hb, Htc ve ferritin ortalamaları arasındaki fark anlamlı olarak saptandı $(p<0.005)$. Aynı hastaların tedavi sonrası 40.gün 1.grupta $\mathrm{Hb}$ değerleri ortalaması 11.7 \pm 0.7 (10-13) g/L, Htc değerleri ortalaması 36.6 \pm 2.0 (33-42) g/L ve ferritin değerleri ortalaması 245 296.8 (68-598) g/L olarak belirlendi. 2.grupta ise $\mathrm{Hb}$ değerleri ortalaması $11.8 \pm 0.7$ (10-13) g/L, Htc değerleri ortalaması 36.2 2.1 (32-40) $\mathrm{g} / \mathrm{L}$ ve ferritin değerleri ortalaması 186 \pm 78.6 (11-480) g/L idi. 40.gün bakılan değerler arasında anlamlı fark saptanmadı (Tablo 2).
Her iki grupta da ciddi yan etkiler saptanmadı. Grup 1'deki hastalardan 2 kadında (\%1.8) ilacın infüzyonu sırasında başağrısı oluşurken, 4 kadında (\%3.6) flushing oluştu. İki (\%1.8) kadın titreme hissederken, 1 (\%0.9) kadın yorgunluk hissi olduğunu söyledi. Ancak bu etkilerin hiçbirisi kalıcı ya da ilerleyici olmadı. İnfüzyon sırasında ya da infüzyon sonrasında gözlenen herhangi bir hemodinamik sıkıntı olmadı. 2.gruptaki hastaların \%31'i (31 kadın) yan etkilerden şikayetçi idi. Bu yan etkiler dispepsi, bulantı ve kabızlık gibi genel gastrointestinal sistem kaynaklı idi. 15 (\%15) kadında ağızda tat değişikliği, metalik tat hissinden şikayetçi idi. Bu semptomlara rağmen hastalar genel olarak ilaca uyum sağladılar ve tedaviyi tamamladılar. Yan etkiler açısından gruplar arası orana bakıldığında 2.grupta yan etkiden şikayetçi olma oranı anlamlı derecede yüksekti $(p<0.005)$ (Tablo 3$)$.

Tablo 2. Tedavi Öncesi ve Sonrası Hb, Htc ve Ferritin Değerleri

\begin{tabular}{|c|c|c|c|}
\hline & $\begin{array}{c}\text { 1. Grup } \\
\text { Intravenöz Demir } \\
(\mathrm{n}: 100) \\
\text { Mean } \pm \text { SD }\end{array}$ & $\begin{array}{l}\text { 2.Grup } \\
\text { Oral Demir } \\
\text { (n:100) } \\
\text { Mean } \pm \text { SD }\end{array}$ & p Değeri \\
\hline $\begin{array}{l}\text { Doğum öncesi Hb (g/L) } \\
\text { Doğum öncesi Htc (g/L) }\end{array}$ & $\begin{array}{c}11.9 \pm 1.0(7-12) \\
32.6 \pm 2.8(24-39)\end{array}$ & $\begin{array}{c}10.3 \pm 1.0(8-12) \\
32.7 \pm 2.9(28-39)\end{array}$ & $\begin{array}{l}0.005 \\
0.732\end{array}$ \\
\hline $\begin{array}{l}\text { Doğum sonrası 1. Gün Hb (g/L) } \\
\text { Doğum sonrası 1. Gün Htc (g/L) } \\
\text { Doğum sonrası 1.Gün Ferritin (g/L) }\end{array}$ & $\begin{array}{c}8.5 \pm 0.8(7-10) \\
27.7 \pm 1.9(22-32) \\
34.9 \pm 43.6(6.1-239)\end{array}$ & $\begin{array}{c}9.1 \pm 0.9(6.9-11.5) \\
29.3 \pm 2.7(22.5-35.9) \\
27.6 \pm 21.4(6.1-86.5)\end{array}$ & $\begin{array}{l}0.005 \\
0.005 \\
0.135\end{array}$ \\
\hline $\begin{array}{l}\text { Tedavi sonrası 14. Gün Hb (g/L) } \\
\text { Tedavi sonrası 14. Gün Htc (g/L) } \\
\text { Tedavi sonrası 14. Gün Ferritin (g/L) }\end{array}$ & $\begin{array}{c}11.1 \pm 1.3(7-14) \\
37.2 \pm 2.9(32-43) \\
463.8 \pm 402.2 \\
(19-262)\end{array}$ & $\begin{array}{c}10.6 \pm 1.2(7.9-14) \\
35.1 \pm 4.1(27-44.9) \\
84.9 \pm 204.5 \\
(4.4-1071)\end{array}$ & $\begin{array}{l}0.005 \\
0.005 \\
0.005\end{array}$ \\
\hline $\begin{array}{l}\text { Tedavi sonrası 40. Gün Hb (g/L) } \\
\text { Tedavi sonrası 40. Gün Htc (g/L) } \\
\text { Tedavi sonrası 40. Gün Ferritin (g/L) }\end{array}$ & $\begin{array}{c}11.7 \pm 0.7(10-13) \\
36.6 \pm 2.0(33-42) \\
245 \pm 96.8(68-598)\end{array}$ & $\begin{array}{c}11.8 \pm 0.7(10-13) \\
36.2 \pm 2.1(32-40) \\
186 \pm 78.6(11-480)\end{array}$ & $\begin{array}{c}0.551 \\
0.256 \\
0.08\end{array}$ \\
\hline Hb: hemoglobin , Htc: hematokrit & & & \\
\hline
\end{tabular}

Tablo 3. Illaca Bağlı Yan Etkiler

\begin{tabular}{|c|c|c|c|}
\hline & $\begin{array}{c}\text { 1. Grup } \\
\text { İntravenöz Demir } \\
(\mathrm{n:100)}\end{array}$ & $\begin{array}{l}\text { 2. Grup } \\
\text { Oral Demir } \\
\text { (n:100) }\end{array}$ & P Değeri \\
\hline $\begin{array}{l}\text { Total } \\
\text { Başağrısı } \\
\text { Flushing } \\
\text { Titreme } \\
\text { Yorgunluk } \\
\text { Tad Değişikliği } \\
\text { Kabızlık }\end{array}$ & $\begin{array}{c}9(\% 9) \\
2(\% 1.8) \\
4(\% 3.6) \\
2(\% 1.8) \\
1(\% 0.9) \\
0 \\
0\end{array}$ & $\begin{array}{c}31(\% 31) \\
0 \\
0 \\
0 \\
0 \\
15(\% 15) \\
16(\% 16)\end{array}$ & 0.005 \\
\hline
\end{tabular}




\section{Tartışma}

Ferrik karboksimaltoz, oral tam terapötik dozlarda demir tedavisine kıyasla, hemoglobin düzeyinde daha kısa sürede ve daha büyük ölçüde artışa sebep olmaktadır [9]. Ağır anemi olgularında da ferrik karboksimaltozun oral demir tedavisine göre etkinliğinin daha fazla olduğu gösterilmiştir $[9,17]$. Bulgularımız postpartum kadınlarda son zamanlarda yayınlanan demir karboksimaltoz ve oral demir ile ilgili çalışmaları doğrulamaktadır. Sonuçlarımız postpartum anemi tedavisinde ferrik karboksimaltozun klinik faydasını göstermektedir.

Ferrik karboksimaltoz, ferritin ile ölçülen demir depolarının iyileştirilmesinde oral demirden üstündür ve eritropoez için mevcut demir göstergesi olan serum transferrin saturasyonunu artırmaktadır [9]. Demir depolarının yenilenmesi önemli bir klinik husustur çünkü indirgenmiş demir depoları hastayı demir eksikliği anemisinin yeniden ortaya çıkması için yüksek risk altında tutar [9]. Oral demir tedavisinde demir depolarının yenilenmesi daha uzun sürede ve daha az etkinlikte olmaktadır [18]. Bu durum ciddi postpartum anemisi olan hastalarda özellikle menstruasyon yeniden başladığında, tekrarlayan anemi riski yüksek olan hastalarda ve özellikle de demir eksikliği sonraki gebeliklerde ileriye taşınabileceği için kaygı uyandırmaktadır [18]. Bulgularımız demir depolarının intravenöz ferrik karboksimaltoz tedavisi ile daha hızlı olarak doldurulduğunu göstermektedir.

İntravenöz ferrik karboksimaltoz hızlı etkilidir çünkü plazmadan hızla çıkarılır ve eritropoez için kullanılır. Bolus dozda verilmesinde sonra, plazma seviyeleri 10 dakikada zirve yapar. Kemik iliğine derhal dahil olduğu pozitron emisyon tomografi çalışmaları ile gösterilmiştir [19]. Çoğunlukla şiddetli anemisi olan böbrek hastalarını araştıran bu çalışmalar, demirin \% 70-97' sinin eritropoez için kullanıldığını, sadece\% 4-6'ık kısmının elimine edildiğini göstermiştir [5].

Klinik çalışma ortamının dışında, oral demir tedavisine uyumsuzluk 2 haftalık tedaviden sonra \%10, 1 ay sonra $\% 25$ ve 2 ay sonra $\% 32$ şeklindedir [20,21]. Bu yüksek başarısızlık oranları göz önüne alındığında, birçok hasta anemi ile ilişkili semptomlara ve transfüzyon gibi artan müdahale riskine maruz kalır. Bu çalışmada, ferrik karboksimaltoz anemide uzamış oral demir tedavisine uyum gerekmeden klinik bir iyileşme sağlamıştır.

Parenteral demirin etkin kullanımı, daha kısa tedavi süresine rağmen doğum sonrası aneminin tedavisinde oral demir sülfat kadar etkili olduğu ve daha düşük toplam demir dozu gerektirdiği başka çalışmalarda da vurgulanmaktadır [18]. Bütün bu sonuçlar ferrik karboksimaltozun, demirin hızlı bulunabilirliğinin önemli olduğu rekombinant insan eritropoietini (rHuEpo) tedavisi alan hastalar dahil, ağır anemisi olan hastalarda avantajlı olabileceğini de göstermektedir [22].
Intravenöz demir preparatlarını kullanmada yüksek anafilaktoid riskleri nedeniyle büyük bir isteksizlik vardır. Ancak, demir karboksimaltoz diğer parenteral demir preparatlarına göre çeşitli avantajlara da sahiptir. Dekstran içermez ve dekstran antikorlarla reaksiyona girmez ve bu nedenle demir dekstran ile görülen tipte anaflaktik reaksiyon riski yoktur [23]. Ek olarak, demir karboksimaltoz daha düşük $\mathrm{pH}$, düşük ozmolarite ve daha yüksek tek doz uygulama içeren demir sükroz (Venofer ${ }^{\mathrm{TM}}$, Vifor International, StGallen, İsviçre) ile karşılaştırıldığında olumlu özelliklere sahiptir [24]. Güvenlik profili sayesinde, hastalara ayaktan tedavi tesislerinde kısa süreli olarak verilebilir. Metalik tadı, flushing ve enjeksiyon bölgesinde yanma gibi genel olumsuz etkileri de 200 mg'a kadar olan dozlarda \% 0,5 oranında görülmektedir [25].

Oral demir ilaçlarının gastrointestinal yan etkilere neden olduğu bilinmektedir [26]. Gastrointestinal yan etkilerin doza bağlı olduğu düşünülmekte ve daha yüksek dozlarda daha sık görülebilmektedir [20]. Oral demir ile tedavi edilen kadınlarda \%30'a varan sıklıkta gastrointestinal yan etkileri tanımlamaktadır [27]. Demir karboksimaltozun tek doz uygulamalarında hastalar tarafından iyi tolere edildiği gösterilmiştir [18]. Çalışmamızda da demir sülfat grubundaki gastrointestinal bozuklukların daha sık görülme sıklığı diğer çalışmaların bulgularını desteklerken, parenteral ferrik karboksimaltoz grubunda yan etki oranı daha az saptanmıştır. Genel yan etki profili gruplar arasında benzerdir ve tedaviyle ilişkili ciddi yan etkiler yoktur. Demir karboksimaltoz, oral demir desteğini tolere edemeyen postpartum anemili hastaların veya demir depolarının hızı bir şekilde yenilenmesini gerektiren hastaların tedavisinde ideal olarak uygundur.

Anemili kadınların artmış kardiyovasküler yük, düşük egzersiz performansı ve baş ağrısı, yorgunluk ve baş dönmesi gibi çeşitli semptomları yaşadıkları bilinmektedir. Tüm bu belirtiler özellikle yenidoğan için bakım yaparken oldukça zayıflatıcı ve zorlayıcı olabilir. Erken görülen doğum sonrası anemi, kadınlar da doğum sonrası depresyon gelişme riskini de artırabilir. Bulgularımız hızlı gelişen aneminin semptomatik rahatlaması üzerindeki etkilerini değerlendirmek için yararlı olacaktır. Çalışmamızda intravenöz demir tedavisinin postpartum anemisi olan kadınlarda hem demir depolarının hem de hemoglobinin hızlı bir şekilde yükselmesini sağladığı görülmüştür. Bununla birlikte, infüzyon risklerini ve bunun getireceği klinik durumları incelemek için daha büyük çalışmalara intiyaç vardır.

\section{Çıkar çatışması / finansal destek beyanı}

Çalışmayı maddi olarak destekleyen kişi / kuruluş yoktur ve yazarların çıkara dayalı bir ilişkisi yoktur. 


\section{Kaynaklar}

1. Bailie GR, Mason NA, Valaoras TG. Safety and tolerability of intravenous ferric carboxymaltose in patients with iron deficiency anemia. Hemodial Int 2010; 14: 47 - 54.

2. Bashiri A, Burstein E, Sheiner E, Mazor M. Anemia during pregnancy and treatment with intravenous iron: review of the literature. Eur J Obstet Gynecol Reprod Biol 2003; 110: 2 - 7.

3. Bodnar LM, Scanlon KS, Freedman DS, Siega-Riz AM, Cogswell ME. High prevalence of postpartum anemia among low-income women in the United States. Am J Obstet Gynecol 2001; 185: 438 - 43.

4. Bodnar LM, Cogswell ME, McDonald T. Have we forgotten the significance of postpartum iron deficiency? Am J Obstet Gynecol 2005; 193: 36-44.

5. Bhandal N, Russell R. Intravenous versus oral iron therapy for postpartum anaemia. Br J Obstet Gynaecol 2006; 113: 1248- 52.

6. Beard JL, Hendricks MK, Perez EM et al. Maternal iron deficiency anemia affects postpartum emotions and cognition. J Nutr 2005; 135: 267-72.

7. Ahmed K, Saqid I, Yousuf AW. Injectable iron therapy: intramuscular vs. intravenous therapy. Biomedics 2000; 16:44-47.

8. Pernoll ML. Iron deficiency anemia. In: Pernoll ML (ed). Benson and Pernoll's handbook of obstetrics and gynecology10th ed. Columbus $(\mathrm{OH})$ : The McGraw-Hill Companies, Inc; 2001. p. 435-7.

9. Seid MH, Derman RJ, Baker JB, Banach W, Goldberg C, Rogers R. Ferric carboxymaltose injection in the treatment of post partum iron defi ciency anemia: a randomized controlled clinical trial. Am J Obstet Gynecol 2008; 199: 4351 - 57.

10. James A, Patel S, Dinh Q. Impact of anemia on medical resource utilization and hospital cost in women with obstetrical bleeding. Blood 2007; 110: 5168 [Abstract].

11. Danielson BG, Geisser P, SchneiderW [eds]. Iron therapy with special emphasis on intravenous administration. 1st ed. St. Gallen, Switzerland: Vifor (International) Inc; 1996.

12. Huch R, Breymann C. Anaemia in pregnancy and postpartum. 2nd ed. Bremen, Germany: Uni-Med Science Verlag; 2006.

13. Chamate E. Treatment of iron deficiency anemia in pregnancy and the immediate puerperium and other ferropenic conditions with saccharated iron administered intravenously in fractionated doses. Abstract at XIVth International Congress of Haematology; 1972; 1972. Sao Paolo, Brasil.

14. Auerbach M, Coyne D, Ballard H. Intravenous iron: from anathema to standard of care. Am J Hematol 2008; 83: 580 - 88.
15. Seid MH, Mangione A, Valaoras TG et al. Safety profile of iron carboxymaltose, a new high dose intravenous iron in patients with iron deficiency anemia. Blood 2006; 108: 3739 [Abstract].

16. Breymann C, Honegger C, Holzgreve W, Surbek D. Diagnosis and treatment of iron deficiency anaemia during pregnancy and postpartum. Arch Gynecol Obstet 2010; 282: 577-80.

17. Van Wyck DB, Martens MG, Seid MH, Baker JB, Mangione A. Intravenous ferric carboxymaltose compared with oral iron in the treatment of postpartum anemia: A randomized controlled trial. Obstet Gynecol 2007; 110: 267-78.

18. Breymann C, Gliga F, Bejenariu C, Strizhova N. Comparative efficacy and safety of intravenous ferric carboxymaltose in the treatment of postpartum iron deficiency anemia. International Journal of Gynecology and Obstetrics 2008; 101:67-73

19. Beshara S, Lundqvist $H$, Sundin J, Lubberink M, Tolmachev $V$, Valind $S$, et al. Pharmacokinetics and red cell utilization of iron (III) hydroxidesucrose complex in anaemic patients: a study using positron emission tomography. $\mathrm{Br}$ J Haematol 1999; 104: 296-302.

20. Hallberg L, Ryttinger L, Sölvell L. Side-effects of oral iron therapy: A double-blind study of different iron compounds in tablet form. Acta Med Scand Suppl 1966; 459: 3-10.

21. Bonnar J, Goldberg A, Smith JA. Do pregnant women take their iron? Lancet 1969; 1: 457-58.

22. Breymann C. The use of iron sucrose complex for anemia in pregnancy and the postpartum period. Semin Hematol 2006; 43: 628-31.

23. Burns DL, Mascioli EA, Bistrian BR. Parenteral iron dextran therapy: a review. Nutrition 1995; 11: 163-68.

24. Venofer: iron sucrose injection USP. Full prescribing information. http://www.venofer.com/VenoferHCP/ images/Venofer_Package.pdf.

25. Perewunsnyk G, Huch R, Huch A, Breymann C. Parenteral iron therapy in obstetrics: 8 years experience with ironsucrose complex. Br J Nutr 2002; 88: 3-10.

26. Crichton R, Danielson B, Geisser P. Iron therapy. Bremen, Germany: Uni-Med Verlag; 2005.

27. Al-Momen AK, al-Meshari A, al-Nuaim L, Saddique A, Abotalib $Z$, Khashogji T, et al. Intravenous iron sucrose complex in the treatment of iron deficiency anemia during pregnancy. Eur J Obstet Gynecol Reprod Biol 1996; 69: 121-24. 